\title{
Malignant inflammation in cutaneous T-cell lymphoma—a hostile takeover
}

\author{
Thorbjørn Krejsgaard $^{1} \cdot$ Lise M. Lindahl ${ }^{2} \cdot$ Nigel P. Mongan ${ }^{3}$ • \\ Mariusz A. Wasik ${ }^{4}$ - Ivan V. Litvinov ${ }^{5}$ Lars Iversen $^{2}$. \\ Erik Langhoff ${ }^{6} \cdot$ Anders Woetmann $^{1} \cdot$ Niels Odum $^{1}$
}

Received: 9 September 2016 / Accepted: 14 September 2016 / Published online: 7 October 2016

(C) The Author(s) 2017. This article is published with open access at Springerlink.com

\begin{abstract}
Cutaneous T-cell lymphomas (CTCL) are characterized by the presence of chronically inflamed skin lesions containing malignant $\mathrm{T}$ cells. Early disease presents as limited skin patches or plaques and exhibits an indolent behavior. For many patients, the disease never progresses beyond this stage, but in approximately one third of patients, the disease becomes progressive, and the skin lesions start to expand and evolve. Eventually, overt tumors develop and the malignant $\mathrm{T}$ cells may disseminate to the blood, lymph nodes, bone marrow, and visceral organs, often with a fatal outcome. The transition from early indolent to progressive and advanced disease is accompanied by a significant shift in the nature of the tumor-associated inflammation. This shift does not appear to be an epiphenomenon but rather a critical step in disease progression. Emerging evidence supports that the malignant $\mathrm{T}$ cells take control of the inflammatory
\end{abstract}

This article is a contribution to the special issue on Cancer and Autoimmunity - Guest Editor: Mads Hald Andersen

Thorbjørn Krejsgaard

thorkr@sund.ku.dk

Niels Odum

ndum@sund.ku.dk

1 Department of Immunology and Microbiology, University of Copenhagen, Blegdamsvej 3c, DK-2200 Copenhagen N, Denmark

2 Department of Dermatology, Aarhus University Hospital, Aarhus, Denmark

3 School of Veterinary Medicine and Science, University of Nottingham, Loughborough, UK

4 Department of Pathology and Laboratory Medicine, University of Pennsylvania, Philadelphia, PA, USA

5 Division of Dermatology, University of Ottawa, Ottawa, ON, Canada

6 James J. Peters VA Medical Center, Veterans Affairs, Bronx, NY, USA environment, suppressing cellular immunity and anti-tumor responses while promoting a chronic inflammatory milieu that fuels their own expansion. Here, we review the inflammatory changes associated with disease progression in CTCL and point to their wider relevance in other cancer contexts. We further define the term "malignant inflammation" as a pro-tumorigenic inflammatory environment orchestrated by the tumor cells and discuss some of the mechanisms driving the development of malignant inflammation in CTCL.

Keywords Cutaneous T-cell lymphoma $\cdot$ Malignant T cells . Inflammation $\cdot$ Pathogenesis $\cdot$ Cancer $\cdot$ Infection $\cdot$ Mycosis fungoides $\cdot$ Sézary syndrome

\section{Introduction}

Cutaneous T-cell lymphomas (CTCL) are characterized by the presence of malignant $\mathrm{T}$ cells in chronically inflamed skin lesions. Mycosis fungoides (MF) is the predominant clinical variant comprising 54-72\% of all cases [1-3]. Classically, MF presents as erythematous skin patches bearing strong resemblance to benign inflammatory dermatoses. Early disease, which is characterized by limited patches or plaques (Fig. 1a), typically exhibits an indolent behavior and a very favorable prognosis with normal life expectancy [1-3]. For many patients, the disease never progresses beyond this stage, but for about one third of patients the skin lesions start to spread (Fig. 1b, c) and, eventually, overt tumors and generalized erythroderma may develop [2]. In advanced disease, the malignant $\mathrm{T}$ cells can further disseminate to the lymphatic system, blood, bone marrow, and internal organs. There is a stage-dependent decrease in survival, and patients with late stages of CTCL have a median life expectancy of less than 4 years [1-5]. The risk of disease progression rises 
2002

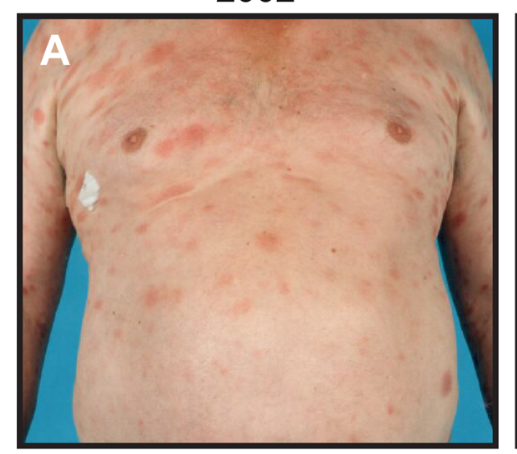

Fig. 1 Progressive MF. a-c Example of a patient with progressive MF that during a 3-year period (2002-2004) presents with increasing skin involvement and inflammation. The patient progressed from a clinical
2003
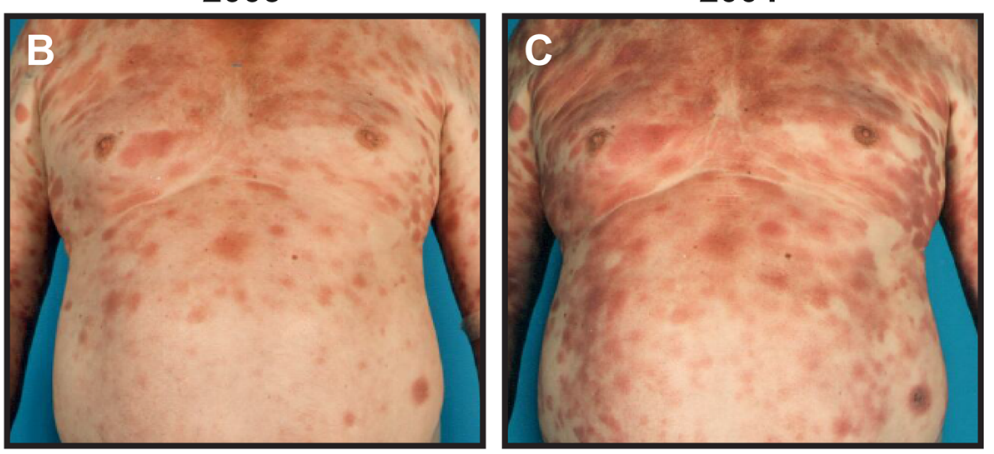

stage IA disease with limited patches and plaques to $\mathbf{b}$, $\mathbf{c}$ clinical stage IB disease with patches and plaques involving more than $10 \%$ of the skin surface area

or fusion proteins. Somatic genetic alterations were, however, frequently found in genes involved in specific cellular processes and signaling pathways, including epigenetic regulation, DNA damage response, cell cycle control, programmed cell death, $\mathrm{T}$ cell receptor (TCR) signaling, as well as the nuclear factor-kappa $\mathrm{B}(\mathrm{NF}-\mathrm{kB})$ and Janus kinase (Jak)/signal transducer and activator of transcription (Stat) pathways [19-25]. Accordingly, numerous studies have previously raised these cellular processes and pathways as key players in the pathogenesis of CTCL. Three studies found a high prevalence of ultraviolet (UV) light signature mutations in patients with MF and leukemic CTCL [19, 22, 25]. No correlation between the presence of the UV light signature and previous therapeutic UV light exposure was observed in leukemic patients, arguing that accumulated lifetime exposure to natural UV light induced the UV mutational signature, thereby challenging the view that the disease originates from central memory $\mathrm{T}$ cells rather than skin resident memory $\mathrm{T}$ cells $[19,22]$.

Despite stage-appropriate treatment, a significant subset of CTCL patients, eventually, develop progressive disease $[2,26]$. Given the profoundly reduced survival and increased clinical aggressiveness of advanced CTCL, it is of outmost importance to map the mechanisms that underlie disease progression $[4,5]$. A better understanding of these mechanisms may lead to the development of more efficient strategies to diagnose, prevent and treat progressive disease. CTCL lesions can display varying degrees of inflammation (Fig. 2), and a large number of studies have highlighted changes in the tumor-associated inflammatory environment as a critical checkpoint in the transition from early indolent to progressive and advanced disease. Here, we review the inflammatory changes associated with disease progression in CTCL and outline some of the mechanisms that appear to drive the development of malignant inflammation-a pro-tumorigenic inflammatory environment orchestrated by the tumor cells. 
Fig. 2 MF lesions display different levels of inflammation. a-c Illustrative skin lesions from a patient with MF displaying varying degrees of inflammation

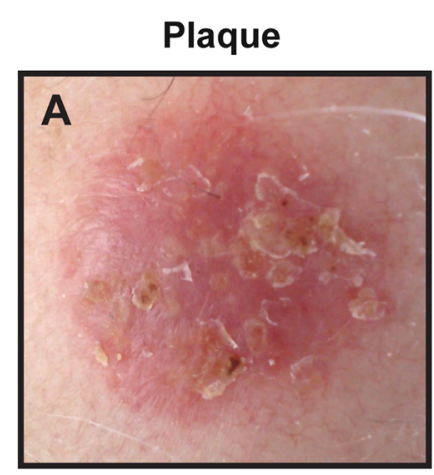

Highly inflamed plaque

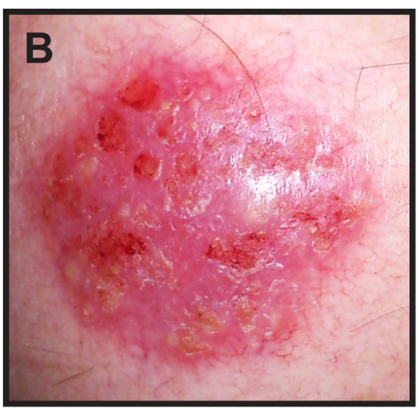

Tumor lesion

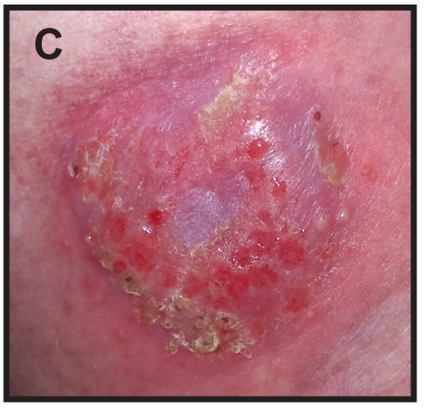

\section{The inflammatory environment becomes Th2-biased during the clinical course of CTCL}

In early disease stages, the skin lesions contain of a small population of malignant $\mathrm{T}$ cells immersed within a dense infiltrate of reactive immune cells. A significant proportion of the immune cells are activated $\mathrm{CD} 8^{+} \mathrm{T}$ cells and $\mathrm{T}$ helper 1 (Th1) cells expressing cytotoxic molecules, implying that early inflammation encompasses a cell-mediated anti-tumor response that actively suppresses the expansion of the malignant cells [27-33]. Indeed, reactive $\mathrm{CD} 4^{+} \mathrm{T}$ cells, $\mathrm{CD} 8^{+} \mathrm{T}$ cells and natural killer (NK) cells isolated from CTCL patients are able to kill autologous malignant $\mathrm{T}$ cells in vitro, and high numbers of $\mathrm{CD}^{+}$lymphocytes in skin lesions and/or blood are linked to a favorable prognosis [30, 32, 34-37].

Disease progression is, however, associated with increasing expression of Th2 markers (e.g., GATA-3) and cytokines (e.g. interleukin (IL)-4, IL-5, and IL-13) concomitant with declining expression of Th1 factors such as T cell-specific Tbox transcription factor (T-bet), interferon gamma (IFN- $\gamma$ ), Stat4, and IL-12 [33, 38-43]. Accordingly, late-stage CTCL is characterized by a $\mathrm{Th} 2$-dominated tumor microenvironment and a paucity of benign Th1 cells and $\mathrm{CD}^{+} \mathrm{T}$ cells [32-34, 37-39, 41]. The growing Th2-bias is believed to be a key process suppressing cellular immunity and anti-tumor responses in CTCL, and the impairment of the immune defense can especially be seen in patients with advanced disease who often suffer from severe and sometimes fatal bacterial infections $[27,44]$.

\section{Changes in the chemokine profile facilitate the development of a Th2-biased tumor microenvironment and direct the trafficking of the malignant $T$ cells}

Parallel to the shift in the balance of Th1 and Th2 cytokines, there is a decrease in chemokines that preferentially attract Th1-associated inflammatory cells, such as CXCL9 and CXCL10, and an increase in chemokines that primarily attract Th2-associated inflammatory cells [14]. For example,
Miyagaki et al. demonstrated that fibroblasts in early CTCL lesions express high levels of the chemokines CXCL9 and CXCL10, which preferentially attract $\mathrm{Th} 1$ cells, $\mathrm{CD} 8^{+} \mathrm{T}$ cells, and NK cells $[45,46]$. Secretion of these chemokines was triggered in explanted CTCL skin fibroblasts upon costimulation with IFN- $\gamma$ and LIGHT (TNFSF14). Whereas the expression of LIGHT was increased in advanced when compared with early disease, the expression of its receptor, herpesvirus entry mediator (HVEM), was decreased. The authors found a direct correlation between the expression levels of CXCL9, CXCL10, and HVEM, indicating that downregulation of HVEM and IFN- $\gamma$, at least partly, is responsible for the decreased expression of CXCL9 and CXCL10 during disease progression [45]. Conversely, the concentrations of Th2associated chemokines such as CCL17, CCL18, CCL22, and CCL26 have been shown to increase from early to advanced disease [47-50]. These chemokines are primarily secreted by diverse non-malignant cell types within the skin lesions, and by favoring recruitment of Th2 cells relative to that of Th1 cells, most likely play a central role in CTCL progression through promoting a Th2-dominated inflammatory microenvironment [7, 46, 47, 50-53].

In early disease, the malignant $\mathrm{T}$ cells express CXCR3, the receptor for CXCL9 and CXCL10, and the CXCR3CXCL9/CXCL10 axis has been proposed to be important for the dermal and epidermal accumulation of the malignant $\mathrm{T}$ cells at this stage. However, similar to CXCL9 and CXCL10, the expression of CXCR3 also decreases during disease progression, which is accompanied by a gradual loss of epidermotropism [12, 13, 45]. In contrast, CCR4, the receptor for CCL17 and CCL22, is continuously expressed by the malignant $\mathrm{T}$ cells and, in line with the upregulation of CCL17 and CCL22, the number of CCR4-positive T cells increases in later disease stages [10, 47, 49]. A recent phase I/II clinical study of the humanized anti-CCR4 antibody, mogamulizumab, showed promising results in heavily pretreated patients, supporting an important role of the CCR4-CCL17/CCL22 axis in the pathogenesis of CTCL [54]. In advanced disease stages, the expression of the chemokine receptor CCR6 and its ligand CCL20 is increased in the lesional skin $[55,56]$. Of interest, Ikeda and co-workers 
reported that disruption of CCL20-CCR6 interactions inhibited disease spread in NOG mice inoculated with $\mathrm{CCR}^{+}{ }^{+} \mathrm{CCL} 20^{+}$malignant CTCL cells, arguing that upregulation of the CCR6-CCL20 axis might promote malignant dissemination in some cases [57]. Collectively, these findings emphasize that the expression of chemokines and chemokine receptors is dynamic during the progression of CTCL, and that distinct chemokine-chemokine receptor interactions shape the inflammatory microenvironment and the trafficking of malignant $\mathrm{T}$ cells at different disease stages.

\section{The expression of pro-tumorigenic cytokines increases during disease progression}

Besides the rise in Th2-associated cytokines and chemokines, the expression of a range of cytokines, including IL-10, IL-15, IL-16, IL-17A, IL-17F, IL-22, and IL-32 also increases during the clinical course of the disease [55, 58-65]. As briefly described below, all of these cytokines have been reported to play pathogenic roles in CTCL. For instance, IL-10 was shown to suppress Thl cytokine production by CTCL cells, and malignant CTCL cells impede dendritic cell maturation, as well as activation of benign T cells, in an IL-10-dependent manner, indicating that IL-10 contributes to the suppression of cellular immunity and anti-tumor responses [66-68]. IL-16 is a growth factor and a chemo-attractant for $\mathrm{CD} 4^{+} \mathrm{T}$ cells. Accordingly, evidence supports that elevated levels of IL-16 contribute to the cutaneous accumulation of the malignant $\mathrm{T}$ cells by augmenting their intradermal proliferation and potentiating their recruitment into the skin $[49,69]$. The expression of IL-17A and IL-17F is heterogeneous and confined to a subset of patients which is likely the cause of discrepant reports regarding their expression in CTCL [55, 62, 70-73]. High expression of IL-17F has been associated with significantly increased risk of disease progression independently of disease stage, sex, and age at the time of diagnosis and IL-17A with neutrophil infiltration in CTCL lesions [62, 70]. In agreement, marked infiltration of neutrophils is only observed in a subset of CTCL patients and their accumulation has been associated with an aggressive disease course [70, 74]. IL-22 has been reported to correlate with the expression of CCL20 in CTCL lesions, and siRNA-mediated knockdown of IL-22 receptor alpha (IL-22RA) in malignant CTCL cells inhibited the expression of CCL20, providing a possible link between IL22, the CCR6-CLL20 axis, and malignant dissemination [55, 56]. Finally, IL-32 has been shown to promote the proliferation and survival of malignant CTCL cells via NF- $\mathrm{KB}$ - and mitogen-activated protein kinase (MAPK)-dependent mechanisms [64, 65].

Taken together, a plethora of distinct cytokines and chemokines are upregulated during the progression of CTCL and seem to facilitate expansion of the malignant $\mathrm{T}$ cells.
Disease progression, thus, appears to be associated with a shift in the nature and cellular composition of the tumor-associated inflammatory environment from partly anti-tumorigenic to pro-tumorigenic. This raises the key question-what is driving these inflammatory changes? Are the changes an epiphenomenon of a frustrated "host" anti-tumor immune response, or are they an important ingredient of a cancer-cell-driven escape from the "host" immunity and a result of a "parasitic" exploitation of the microenvironment orchestrated by the malignant $\mathrm{T}$ cells?

\section{The malignant $T$ cells promote the development of a lesional Th2-bias}

Providing a pivotal clue to this question, several reports have shown that the malignant $T$ cells in advanced stages express high levels of the Th2-cytokines IL-4, IL-5, and IL-13 and low levels of IFN- $\gamma[41,75,76]$. At the molecular level, the skewed Th2 cytokine profile, at least partly, seems to be mediated by a progressive dysregulation of the Jak/Stat pathway and increased expression of the Th2-lineage-specific transcription factor GATA-3 [33, 43]. Under normal conditions, Stat proteins are only transiently activated but genetic alterations, epigenetic changes, persistent cytokine signaling, and infections appear to drive constitutive activation of Stat3, Stat5, and Stat6 signaling in the malignant $T$ cells during the clinical course of CTCL [19, 21, 24, 41, 43, 77-83]. Aberrant activation of these transcription factors not only fosters the growth and survival of the malignant $\mathrm{T}$ cells but also stimulates the secretion of Th2 cytokines [43, 75, 80]. Expression of Stat 4 , which promotes Th1 differentiation and IFN- $\gamma$ expression, is on the contrary very frequently lost in advanced disease [42, 43, 84-86]. Evidence suggests that aberrant activation of Stat5 in the malignant $\mathrm{T}$ cells induces expression of miR-155 which subsequently inhibits the expression of Stat4 $[84,87,88]$. The mechanisms underlying the increased expression of GATA-3 in the malignant T cells have not yet been elucidated. However, it is noteworthy that several large-scale genomic studies recently found that the ZEB1 gene, which is a potent transcriptional repressor of GATA-3, is somatically targeted by deleterious mutations or deleted in $45-65 \%$ of patients with advanced CTCL $[19,21,22,25]$.

It is well established that Th1 cytokines enforce Th1- and repress Th2-mediated inflammation and vice versa, suggesting that the phenotypic shift of the malignant $T$ cells towards a Th2 profile might instigate the development of the generalized Th2-bias in CTCL lesions. Indeed, a recent study by Guenova et al. demonstrated that benign $\mathrm{T}$ cells isolated from patients with leukemic CTCL displayed reduced Th2 and enhanced Th1 responses when cultured separately from the malignant $\mathrm{T}$ cells [76]. Likewise, $\mathrm{T}$ cells from healthy donors demonstrated significantly reduced ability to secrete IFN- $\gamma$ when co- 
cultured with leukemic CTCL cells. The malignant T cellinduced suppression of IFN- $\gamma$ production by the healthy T cells was completely blocked by neutralizing antibodies against IL-4 and IL-13. Notably, separate culture had no effect on the production of Th1 and Th2 cytokines by isolated malignant $\mathrm{T}$ cells. The authors further addressed how treatment with a variety of modalities, including UVB phototherapy, extracorporal photopheresis, low-dose alemtuzumab, and systemic chemotherapy with gemcitabine influenced the frequency of benign T cells expressing IFN- $\gamma$ and IL-4 in leukemic CTCL patients [76]. In line with the in vitro results, they found that in-spite of distinct mechanisms of action, all treatment modalities that successfully reduced the malignant $\mathrm{T}$ cell burden strongly increased the frequency of IFN- $\gamma$-expressing, and decreased the frequency of IL-4-expressing, benign T lymphocytes [76]. Collectively, these findings imply that progressive dysregulation of the Jak/Stat pathway and upregulation of GATA-3 in the malignant T cells lead to their increased synthesis of IL-4 and IL-13 which suppresses benign Th1 responses and promotes a generalized Th2-bias.

Malignant $T$ cells may also contribute indirectly to the shifting Th1/Th2 balance by regulating the expression of chemokines within the lesional skin. Whereas IFN- $\gamma$ preferentially induces expression of CXCL9 and CXCL10, IL-4 and IL-13 primarily induce expression of CCL17, CCL18, CCL22, and CCL26 [46, 89-94]. It is therefore plausible that the increased expression of Th2 cytokines and decreased expression of Th1 cytokines by the malignant $\mathrm{T}$ cells create a positive feedback loop by promoting the secretion of Th2 chemokines from benign cells in the tumor microenvironment (e.g., tumor-associated macrophages, fibroblasts, and keratinocytes). This, in turn, favors the recruitment of Th2 cells, ultimately, leading to enhanced expression of $\mathrm{Th} 2$ and decreased expression of Th1 cytokines. Accordingly, significant correlations between the expression of IL-4 and CCL18, as well as IL-4 and CCL26, in CTCL skin lesions were previously reported $[48,50]$.

\section{The malignant $T$ cells suppress anti-tumor immunity via cell contact-dependent and cell contact-independent mechanisms}

The malignant $\mathrm{T}$ cells may, however, not only suppress antitumor immunity by modulating the nature of the inflammatory microenvironment but can also directly kill or suppress the activation and proliferation of benign immune cells. For example, aberrant activation of Stat5 has been shown to induce expression of the B7 family member, CD80 (B7-1), on the surface of malignant CTCL cells [95]. CD80 is an immunoregulatory molecule that can deliver growth-inhibitory signals to activated T cells via the receptor CD152 (CTLA-4) [96]. Whereas depletion of CD80 in the malignant $\mathrm{T}$ cells did not influence their proliferation or viability, the malignant $\mathrm{T}$ cells inhibited the proliferation of benign T cells in a CD152- and CD80-dependent manner [95]. The Jak/Stat pathway was, likewise, proposed to induce malignant $\mathrm{T}$ cell expression of another inhibitory B7 family member, namely PD-L1 (B7$\mathrm{H} 1$ ), which has been implicated in benign $\mathrm{T}$ cell suppression and tumor immune evasion in CTCL [97-100]. Interestingly, it was demonstrated that the malignant $\mathrm{T}$ cells can be targeted by PD-L1-specific cytotoxic T cells, indicating that the immune system is able to react to immune escape mechanisms of the tumor cells [101]. The malignant $\mathrm{T}$ cells also frequently express high levels of Fas ligand (FasL) which can induce apoptosis by engaging the death receptor, Fas, on target cells [102]. Malignant CTCL cells have been shown to induce FasL-mediated T cell apoptosis in vitro, and the numbers of $\mathrm{CD}^{+} \mathrm{T}$ cells are inversely distributed with FasL-positive tumor cells in situ, supporting that the malignant $\mathrm{T}$ cells utilize FasL to kill tumor-reactive T cells $[102,103]$. Due to loss of Fas expression, somatic inactivating mutations and deletions of the FAS and ARIDIa genes or increased expression of antiapoptotic proteins such as c-FLIP, the malignant T cells typically develop resistance to FasL-mediated apoptosis which contrarily protects them from activation-induced apoptosis and T cell-mediated cytotoxicity [19, 21, 22, 104-107].

In addition to these cell contact-dependent mechanisms, the malignant $\mathrm{T}$ cells may also directly suppress the immune system via secretion of soluble factors. Aberrant activation of the Jak/Stat pathway has, for example, been shown to induce expression of the immunoregulatory cytokines IL-10 and transforming growth factor beta (TGF- $\beta$ ) in malignant CTCL cells $[68,108]$. As noted above, malignant CTCL cells impair DC maturation and activation of benign T cells in an IL-10-dependent manner. Similarly, TGF- $\beta$ was reported to enhance the malignant $T$ cells' ability to inhibit activation of syngenic and allogenic normal T cells $[66-68,109]$. Given the potent immunosuppressive capacities of IL-10 and TGF- $\beta$, it could be expected that they would also inhibit the proliferation and cytokine production of the malignant $\mathrm{T}$ cells in an autocrine fashion. However, as observed with the expression of Fas, malignant $\mathrm{T}$ cells in advanced CTCL frequently lack expression of functional receptors and/or downstream signaling mediators for IL-10 and TGF- $\beta$, essentially rendering them resistant to the suppressive activities of these cytokines [82, 86, 110, 111]. Downregulation of Zeb1 has, notably, been shown to confer resistance to TGF- $\beta$ mediated growth inhibition in malignant $\mathrm{T}$ cells from adult T-cell leukemia/lymphoma [112]. These findings exemplify that malignant $\mathrm{T}$ cells are able to simultaneously exploit and escape suppressive mechanisms normally deployed by the immune system. In a similar fashion, aberrant activation of Stat3 induces constitutive expression of suppressor of cytokine signaling-3 (SOCS3), which attenuates the 
effects of several cytokines, including IFN- $\gamma$ and IFN- $\alpha$ and, consequently, protects the malignant $\mathrm{T}$ cells from cytokine-mediated anti-tumor responses [113]. Altogether, these data clearly indicates that the malignant $\mathrm{T}$ cells become resistant to immunosuppressive factors (e.g., dysfunction of Fas-, IL-10-, and TGF- $\beta$-signaling and upregulation of SOCS3) while acquiring the capacity to inhibit anti-tumor immunity by means of cell contactdependent (e.g., CD80, PD-L1, and FasL) and independent (e.g., Th2 cytokines, IL-10, TGF- $\beta$ ) mechanisms.

\section{The malignant $T$ cells produce autocrine growth factors that activate pro-oncogenic pathways}

The development of a Th2-dominated tumor microenvironment may not merely impede cellular immunity and antitumor responses but also directly fuel the growth of the malignant $\mathrm{T}$ cells. Intriguingly, a recent study by Geskin et al. provided evidence that the malignant $\mathrm{T}$ cells express functional receptors for IL-4 and IL-13, and that these cytokines promote the activation of Stat 6 and the proliferation of the tumor cells [41]. Accordingly, neutralizing antibodies against IL-4 and IL-13, as well as a Stat6 inhibitor, significantly retarded the proliferation of $\mathrm{CD}^{+} \mathrm{T}$ cells isolated from leukemic CTCL patients [41]. These findings imply that IL-4 and IL13 produced by malignant $\mathrm{T}$ cells and benign $\mathrm{Th} 2$ cells stimulate the proliferation of the malignant $T$ cells via activation of Stat6. Other cytokines that are upregulated in advanced disease, including IL-15, IL-16, and IL-32, can also augment the growth of the malignant $\mathrm{T}$ cells in an autocrine manner [49, $59,61,64,65,114]$. Of particular interest, IL-15 activates Stat5 and Stat3 in malignant CTCL cells and has been proposed to contribute to the aberrant activation of these transcription factors $[43,108,115]$. A possible explanation for the increased expression of IL-15 was provided by a recent study which documented that the promoter region where Zeb1 can bind and repress transcription of IL-15 is hypermethylated in malignant $\mathrm{T}$ cells from leukemic CTCL patients, resulting in impaired binding of Zeb1 and unchecked IL-15 expression [60]. This finding implicates Zeb1 as a putative tumor suppressor of several pathogenic processes in CTCL and suggests that in patients in whom the $Z E B 1$ gene is not mutated, tumor suppressive functions of the Zeb1 protein may instead be impeded by other mechanisms such as epigenetic modification of its target DNA. Interestingly, malignant $\mathrm{T}$ cells are not the only source of IL-15 in the lesional skin, as stromal cells also have the capacity to express IL-15. In particular, epidermal keratinocytes that become activated by malignant $\mathrm{T}$ cells in vitro and in vivo, have been shown to express IL-15 in situ in CTCL lesions, indicating that malignant $\mathrm{T}$ cells may also propagate their own proliferation through stimulation of keratinocytes to produce tumor growth factors such as IL-15
$[114,116]$. The fact that transgenic mice overexpressing IL-15 develop a neoplasm that mimics human CTCL reinforces the idea that IL-15 plays an important role in the disease pathogenesis [60].

Constitutive activation of the transcription factor NF- $\mathrm{KB}$ is, like dysregulation of the Jak/Stat pathway, a characteristic feature of malignant CTCL cells and numerous reports have demonstrated that NF- $\mathrm{KB}$ promotes their proliferation and survival $[117,118]$. It was recently reported that IL-32 stimulates the growth of malignant CTCL cells in a NF-KB-dependent manner. This finding provides circumstantial evidence that upregulation of IL-32 during disease progression may contribute to the constitutive activation of NF- $\mathrm{KB}$ [65]. Altoghether, these data illustrate that in advanced disease the malignant $\mathrm{T}$ cells produce cytokines (e.g., IL-4, IL-13, IL-15 and IL-32), which can induce chronic activation of key pro-oncogenic signaling pathways in an autocrine manner. The arsenal of autocrine growth factors that the malignant $\mathrm{T}$ cells are able to produce is not limited solely to cytokines. For example, it has been shown that the malignant $\mathrm{T}$ cells begin to express cyclooxygenase-2 (COX-2) in plaque-stage disease, and that the expression of this protein correlates with in vitro secretion of its downstream product, prostaglandin E2 (PGE2) [119]. Selective knockdown of COX-2 or PGE2 receptor antagonists inhibited the spontaneous proliferation of the malignant $\mathrm{T}$ cells in vitro [119]. Furthermore, the COX-2 inhibitor, celecoxib, reduced tumor growth in a xenograft model of advanced MF, implicating PGE2 as an autocrine growth factor in CTCL [120]. PGE2 is known to hamper cell-mediated immunity by various mechanisms. These include inhibition of Th1 cytokine production, repression of CXCL9 and CXCL10 expression as well as suppression of NK cell- and $\mathrm{CD}^{+} \mathrm{T}$ cellmediated cytotoxicity [121]. Hence, analogous to IL-4 and IL13, PGE2 may have a dual function in malignant inflammation by hampering cellular immunity while directly stimulating the growth of the malignant $\mathrm{T}$ cells. In summary, the malignant $\mathrm{T}$ cells appear to gain the capacity to produce a spectrum of cytokines and other inflammatory factors that can promote activation of pro-oncogenic pathways and stimulate their own expansion.

\section{The malignant $T$ cells foster pro-tumorigenic inflammation through interactions with stromal and innate immune cells}

In line with the growing Th2-bias and malignant T cell expression of factors such as PGE2, IL-10, and high-mobility group BOX-1 protein (HMGB1), the infiltration of mast cells, eosinophils, and tumor-associated macrophages (TAMs) with an M2 phenotype, typically increases during CTCL progression [89, 122-127]. A high degree of infiltration by each of these immune subsets has been linked to poor prognosis, suggesting 
that the malignant $\mathrm{T}$ cells may foster a pro-tumorigenic environment by promoting accumulation of granulocytes and TAMs [122, 123, 127]. Accordingly, Rabenhorst et al. demonstrated that mast cells in CTCL lesions generally exhibit a degranulated phenotype, and that their numbers correlate with the microvessel density [122]. Supernatant from activated mast cells was further able to promote the proliferation of malignant CTCL cells in vitro, and depletion of mast cells in a murine $\mathrm{T}$ cell lymphoma model inhibited tumor growth, strongly supporting that mast cells play a pro-tumorigenic role in CTCL [122]. In a similar manner, eosinophils often display an activated phenotype and express IL-5 in CTCL skin lesions, indicating that they release inflammatory factors into the tumor microenvironment that may aggravate the disease [123]. Indeed, accumulation of eosinophils in blood and lesional skin of CTCL patients has not only been associated with poor prognosis but also with increased pruritus [6]. Activated eosinophils can, in addition to IL-5, release high levels of IL-4 and IL-13 as well as angiogenic factors. This raises the possibility that malignant $\mathrm{T}$ cells, through the attraction and activation of eosinophils, may fuel their own growth indirectly by boosting neovascularization and a deregulated Th2 response [128]. Marked infiltration of neutrophils is only occasionally seen in CTCL, but detection of neutrophilic dermatoses has been associated with an aggressive disease course [70, 74]. As already mentioned, L-17A and IL-17F are expressed in the lesional skin in a subset of CTCL patients and known to stimulate recruitment of neutrophils $[62,70,71]$. High expression of IL-17A has, accordingly, been associated with neutrophilic infiltration into CTCL lesions; whether it is also the case for IL-17F remains to be investigated [70]. Malignant $\mathrm{T}$ cells derived from some patients have the capacity to express IL-17A and/ or IL-17F via a Jak3/Stat3/Stat5-dependent mechanism but do not express the Th17-linage transcription factor, RORc, or display a characteristic Th17-phenotype [62, 71, 76, 129]. Therefore, expression of IL-17A and IL-17F by the malignant T cells is probably not reflective of Th17 origin, or acquisition of a full-fledged Th17 phenotype, but rather a consequence of dysregulated signaling. Several cell types, including Th17 cells, mast cells and neutrophils are also known to produce IL-17 cytokines and it is likely that they also provide a significant source of IL-17A and IL-17F in some lesions. Accordingly, skin-infiltrating neutrophils and mast cells have been reported to stain positive for IL-17 in CTCL patients with neutrophilic dermatoses [72].

The malignant $\mathrm{T}$ cells can also exploit monocytes and dendritic cells to stimulate their expansion. For example, malignant CTCL cells engage in cell contact-dependent crosstalk with immature dendritic cells ex vivo that results in prolonged survival and proliferation of both the malignant $\mathrm{T}$ cells and the immature dendritic cells. The malignant $\mathrm{T}$ cells have, interestingly, been shown to arrest dendritic cells in an immature state via secretion of regulatory cytokines such as IL-10, indicating that they block dendritic cell maturation to perpetuate their own growth and maintain a tolerogenic environment $[67,130]$.

M2-like TAMs are generally believed to contribute to tumorigenesis by promoting angiogenesis, matrix remodeling and inhibition of adaptive immunity [131]. In agreement with the notion that the malignant $\mathrm{T}$ cells drive the accumulation of M2-like TAMs during the clinical course of CTCL, M2-like macrophages were found to be abundant within the tumor microenvironment, but not in the spleen, in a CTCL mouse model [126]. Furthermore, effective treatment of CTCL patients resulting in decreased numbers of tumor cells was shown to be accompanied by a strong decrease of dermal TAMs in the lesional skin [127]. TAMs express CCL18 and MMP9 in CTCL lesions, and clodronate-mediated depletion of M2-like macrophages in a mouse model of CTCL inhibited angiogenesis, lymphangiogenesis, and tumor development. Collectively, these results implicate M2-like TAMs in vascularization, chemotaxis, tissue remodeling, and tumor growth in CTCL [51, 126, 132].

The malignant $\mathrm{T}$ cells also display aberrant release of cytokines and other factors, such as vascular endothelial growth factor (VEGF), prostaglandins, and lymphotoxins, which promote activation of endothelial cells and fibroblasts, thereby stimulating angiogenesis via both direct and indirect mechanisms $[62,70,71,81,119,133,134]$. For example, the malignant $\mathrm{T}$ cells can trough release of VEGF-A and lymphotoxin $\alpha$ induce enhanced endothelial sprouting in vitro and further trigger fibroblast expression of VEGF-C and angiogenesis in vivo, supporting the concept that the malignant $\mathrm{T}$ cells orchestrate profound changes in the tumor microenvironment $[133,135]$. Indeed, the malignant $\mathrm{T}$ cells strongly impacted skin structure, as well as keratinocyte activation and proliferation, in an organotypic skin model and a xenograft CTCL mouse model [116]. Hence, malignant T cells and their supernatants triggered Jak and MAPK activation in keratinocytes, downregulation of differentiation markers such as keratin 10 and involucrin, epidermal hyperproliferation, disorganized keratinocyte stratification, and decreased barrier formation, thus mimicking many features seen in CTCL lesions [116]. In conclusion, accumulating evidence indicates that the malignant $\mathrm{T}$ cells, via interactions with stromal and benign immune cells, drive the disease stagerelated inflammatory changes observed in CTCL.

\section{Drugs that stimulate cellular immunity induce disease regression}

As highlighted by the multiple pieces of evidence outlined above, the shift from a Th1- towards a Th2-dominated tumor-associated inflammatory environment appears to play a 
central role in malignant $\mathrm{T}$ cell proliferation and tumor promotion and, at the same time, suppression of cell-mediated immunity and anti-tumor responses in CTCL. Consistent with this conclusion, administration of the Th1 cytokines IL-12 and IFN- $\gamma$ can induce lesional regression associated with increased numbers of cytotoxic $\mathrm{CD} 8^{+} \mathrm{T}$ cells in the resolving skin, and treatment with Toll-like receptor (TLR) agonists that stimulate cellular immunity have shown clinical efficacy in CTCL patients [136-144]. For example, a recent clinical phase 1 trial reported that $75 \%$ of the enrolled CTCL patients had significant improvement in skin lesions treated topically with resiquimod gel (TLR-7 and TLR-8 agonist) and 30\% had clearing of all treated lesions. Some patients even had a systemic response with improvement of untreated lesions. The responding patients displayed profoundly decreased numbers of malignant $\mathrm{T}$ cells, and high responses were associated with recruitment and expansion of benign $\mathrm{T}$ cell clones in treated skin, increased skin $\mathrm{T}$ cell effector functions and a trend towards increased NK cell function [144]. The fact that immunomodulatory drugs, which stimulate the cellular immune system, can induce lesional regression and promote eradication of the malignant $T$ cells strongly supports that suppression of the patients' cellular immunity represents a critical checkpoint for the expansion of the malignant $\mathrm{T}$ cells.

\section{Enterotoxin-producing $S$. aureus may promote malignant inflammation in CTCL}

Aberrant activation of the Jak/Stat pathway seems to be a central event in the development of malignant inflammation in CTCL. A significant proportion of patients with advanced disease, accordingly, display genetic alterations that directly or indirectly promote constitutive activation of the Jak/Stat pathway; however, it is unclear what drives constitutive activation of Jak/Stat signaling in other patients [19, 21, 24, 25]. Due to a compromised cutaneous barrier and evolving immune dysfunction, the lesional skin of CTCL patients is often colonized with enterotoxinproducing Staphylococcus aureus which represent a major clinical problem [18, 44, 145-147]. Recent reports have demonstrated that staphylococcal enterotoxins (SE) instigate crosstalk between the malignant and benign $\mathrm{T}$ cells which leads to increased proliferation, activation of Stat 3 and expression of Stat3-regulated cytokines in the malignant $\mathrm{T}$ cells [82, 83, 148]. Consequently, colonization of CTCL lesions with SE-producing $S$. aureus may trigger mechanisms that aggravate the disease and promote malignant inflammation. In support of this theory, a series of smaller studies and case reports have shown that antibiotic treatment, leading to successful elimination of $S$. aureus, is associated with significant clinical improvement in most colonized patients. Strikingly, in some patients, antibiotic treatment even resulted in complete clinical response with no residual skin involvement $[18,145,146$, 149, 150]. Evidence suggests that the malignant T cells are responsible for the impairment of the skin barrier in CTCL [116]. This indicates that the malignant $\mathrm{T}$ cells both induce increased susceptibility towards $S$. aureus and subsequently exploit the infection to initiate a vicious crosstalk with the benign $T$ cells which results in activation of pro-oncogenic pathways. These pathways, in turn, promote the proliferation of the malignant $\mathrm{T}$ cells and their expression of protumorigenic factors. Although the proposed mechanism is specific for SE-producing bacteria, it is likely that other infectious agents and extrinsic factors that impact the inflammatory environment may promote malignant inflammation and disease progression. On the other hand, it can be speculated that certain bacteria might be beneficial through their ability to regulate inflammation or out-compete disease-promoting bacteria and, thus, such bacteria may be of therapeutic use in CTCL if identified.

\section{Malignant inflammation-a hostile takeover}

The inflammatory reaction in early indolent disease appears to be a "host" response directed against the malignant $T$ cells and potentially other factors in the tumor microenvironment. Early inflammation, accordingly, involves $\mathrm{CD} 8^{+} \mathrm{T}$ cells, Th1 cells and possibly NK cells in conjunction with cytokines that inhibit the expansion of the malignant $\mathrm{T}$ cells. However, the nature and cellular composition of the tumor-associated inflammatory environment seem to shift from partly antitumorigenic to pro-tumorigenic during disease progression. As reviewed above, considerable evidence suggests that the malignant $\mathrm{T}$ cells orchestrate the shift in the inflammatory microenvironment, enforcing profound changes in the cytokine and chemokine milieu as well as in the composition, activity and function of most cellular components within the cutaneous lesions. These changes, in turn, promote tumorigenic processes, including angiogenesis, lymph-angiogenesis, tissue remodeling, and tumor growth. The malignant $\mathrm{T}$ cells, thus, appear to perform a "hostile" takeover of the lesional microenvironment, thereby gaining control of the tumorassociated inflammation to create a setting that facilitates their own expansion (Fig. 3). The hostile takeover is exemplified by the tumor cell-mediated induction of (i) malignant growth factors such as IL-4, IL-13, and IL-15 from non-malignant cells, (ii) M2-like TAMs, mast cells, and immature dendritic cells that provide growth and survival signals to the malignant $\mathrm{T}$ cells, and (iii) angiogenesis via stimulation of fibroblasts, innate immune cells and endothelial cells. In other words, malignant $\mathrm{T}$ cells engage in a "parasitic" exploitation of benign immune cells and stromal cells to produce protumorigenic growth and survival factors. At the same time, the malignant $\mathrm{T}$ cells express immunosuppressive factors that 

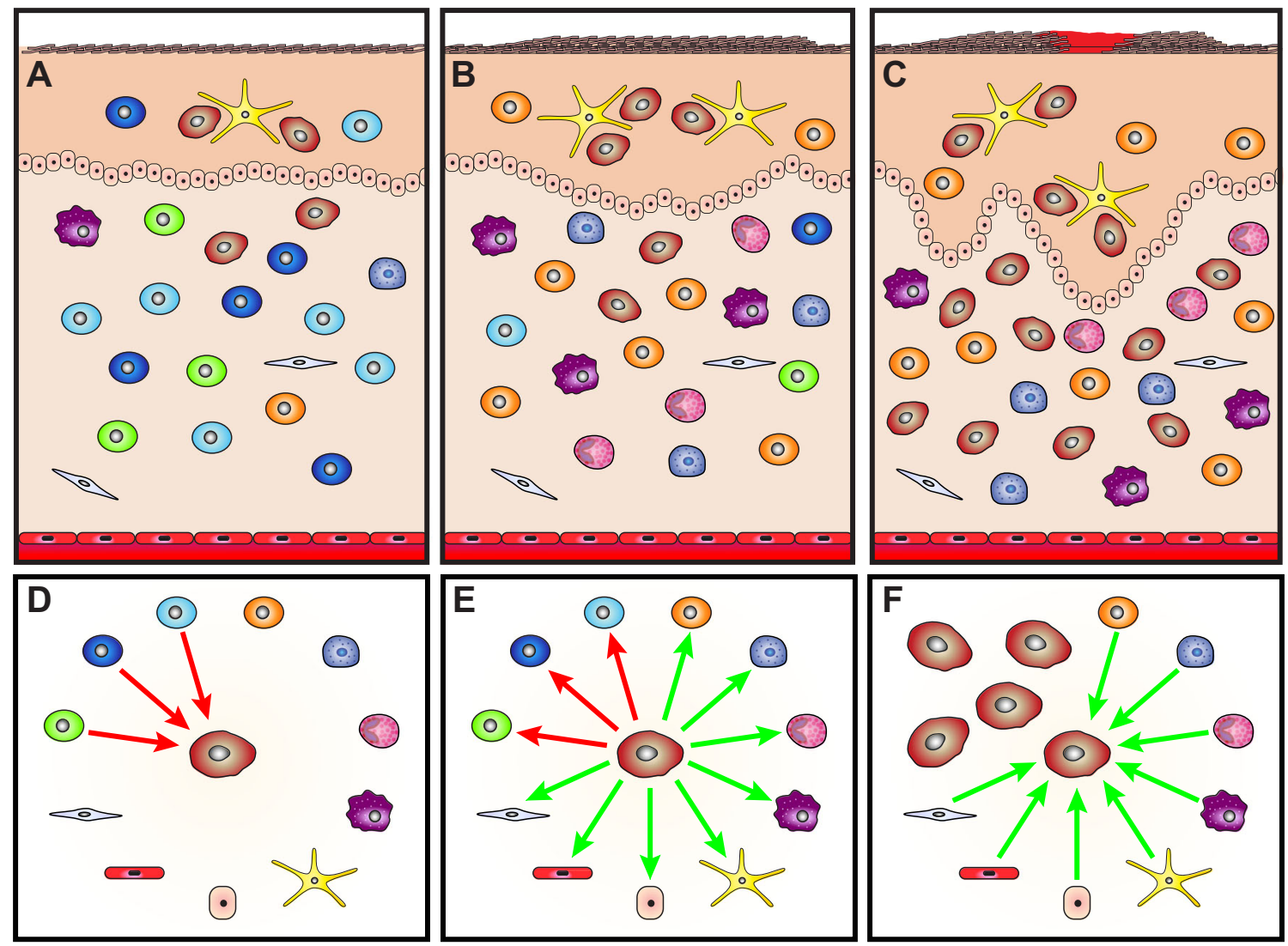
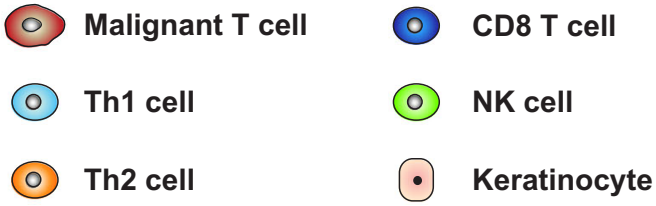

Fig. 3 A model of malignant inflammation. a-c Schematic illustration of progression from a early indolent CTCL with few malignant T cells b, $\mathbf{c}$ to more advanced disease increasingly dominated by Th2-biased inflammation and malignant $\mathrm{T}$ cells. $\mathbf{d}$ In early indolent disease, the expansion of the malignant $\mathrm{T}$ cells is kept in check by a cellular antitumor immune response involving $\mathrm{CD} 8^{+} \mathrm{T}$ cells, Th1 cells, and NK cells. e In time, malignant $\mathrm{T}$ cell endogenous (e.g., genetic and epigenetic

foster an immune-privileged tumor site in part by direct inhibition of non-malignant $\mathrm{T}$ cells and induction of tolerogenic macrophages and dendritic cells.

Although it is not known exactly how the malignant $\mathrm{T}$ cells gain the capacity to impose these changes on the inflammatory environment, a series of recent data suggests that endogenous changes in the malignant $\mathrm{T}$ cells, including somatic mutations, somatic copy number variations, and epigenetic deregulation, may play a critical role [19-25, 60, 151, 152]. Exogenous factors such as bacterial colonization and infection may also drive activation of pro-oncogenic mechanisms and inhibit anti-tumor immunity. In particular, S. aureus and its toxins appear to possess the ability to stimulate malignant exploitation of non-malignant $\mathrm{T}$ cells in a manner which leads to activation of the Jak/Stat pathway and release of immune
Eosinophil

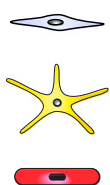

Fibroblast

Mast cell

- M2-like TAM

alterations) and exogenous (e.g., irradiation, toxins, microbes, chemicals, drugs) events can enable the malignant $T$ cells to take control of the tumor microenvironment, thereby inhibiting the cellular anti-tumor immune response while stimulating the accumulation and/or activation of certain types of benign immune cells and stromal cells (f) that produce pro-tumorigenic factors which directly or indirectly foster the survival and expansion of the malignant $\mathrm{T}$ cells

regulatory cytokines such as IL-10. Dysregulation of the $\mathrm{Jak} /$ Stat pathway emerges as a central event in the development of malignant inflammation in CTCL and, indeed, evidence from various other cancers also points towards a central role for certain Stat proteins (e.g., Stat3) in sustaining chronic inflammation while antagonizing anti-tumor responses [153]. Taken together, these findings suggest that disease progression is associated with, and at least partly driven by, changes in the tumor-associated inflammatory environment that are elicited by the malignant $\mathrm{T}$ cells. We suspect that once established, malignant inflammation will stimulate tumor growth and foster deepening of the malignant $\mathrm{T}$ cell phenotype, thereby further enhancing pro-tumorigenic inflammatory processes that may result in a self-perpetuating vicious circle accelerating cancer progression. 


\section{Malignant inflammation in solid cancers}

The importance of the tumor-associated inflammatory environment is now more and more recognized in many solid tumor contexts and models [154-156]. In particular, a bias in Th1/Th2 cell ratio and/or changes in the circulating cytokine profile are increasingly associated with many solid tumor types, including prostate, oral, ovarian, pancreatic, cervical, colorectal, and breast cancers [157-165]. There is also evidence that the tumor-immune environment influences therapeutic responses. Breast cancer is, for example, known to harbor a pro-inflammatory milieu often associated with obesity and increased PGE2 levels [166]. However, patients harboring an increased number of Th1 relative to Th2 cells typically experience superior outcomes [159]. Related to this, a loss of anti-HER2 Th1 cells in breast cancer correlates with poor response to HER2-targetted therapies [161]. The mechanisms underpinning the shift from a Th1 to a Th2 response in nonCTCL cancers are subject of intense research. Recently, it has been shown that polycomb repressive complex mediates epigenetic silencing of the Th1 chemokines, CXCL9 and CXCL10, in ovarian and colorectal cancers, thereby reducing recruitment of $\mathrm{CD} 8^{+} \mathrm{T}$ cells $[162,165]$. Ovarian and colorectal cancer patients with increased numbers of intra-tumoral $\mathrm{CD} 8^{+} \mathrm{T}$ cells or Th1 cells consistently experience better outcomes [158, 162, 165]. Therefore, epigenetic-targeting therapies may potentiate the sensitivity to immuno-therapies by modulating the inflammatory environment. As indicated by these examples, malignant inflammation, as defined here, may also be of importance in solid cancers, suggesting that some of the mechanisms described in CTCL may be of general relevance in cancer.

\section{Conclusions}

In conclusion, recent as well as earlier data support our hypothesis that the malignant $\mathrm{T}$ cells are key drivers of the inflammatory changes observed during disease progression in CTCL, and that these changes inhibit anti-tumor immunity while promoting tumor growth. If correct, this hypothesis predicts that the most effective treatment of progressive and advanced disease should rationally combine therapeutics that directly target the malignant $\mathrm{T}$ cells with drugs that (i) enhance cellular immunity, (ii) neutralize immune evasive mechanisms, (iii) inhibit the pro-tumorigenic environment, and (iv) eliminate pro-oncogenic bacteria such as enterotoxinproducing $S$. aureus in infected patients. Such combined therapeutic strategies would perhaps give a realistic hope for effective treatment, or even a cure, of this devastating disease.

Acknowledgments This work was supported by research funding from the Danish Research Council, the Novo Nordic Foundation, the Novo
Nordic Foundation Tandem program, the Lundbeck Foundation, the Danish Cancer Society (Kræftens Bekæmpelse), and the Danish Cancer Society and TV2 "Knæk-Cancer-Program". TK was further supported by a Sapera Aude Talent Grant (DFF-4092-00122) from the Danish Council for Independent Research.

\section{Compliance with ethical standards}

Conflict of interest The authors declare that they have no conflict of interest.

Open Access This article is distributed under the terms of the Creative Commons Attribution 4.0 International License (http:// creativecommons.org/licenses/by/4.0/), which permits unrestricted use, distribution, and reproduction in any medium, provided you give appropriate credit to the original author(s) and the source, provide a link to the Creative Commons license, and indicate if changes were made.

\section{References}

1. Willemze R, Jaffe ES, Burg G et al (2005) WHO-EORTC classification for cutaneous lymphomas. Blood 105:3768-3785

2. Scarisbrick JJ, Kim YH, Whittaker SJ et al (2014) Prognostic factors, prognostic indices and staging in mycosis fungoides and Sezary syndrome: where are we now? Br J Dermatol 170:1226-1236

3. Wilcox RA (2016) Cutaneous T-cell lymphoma: 2016 update on diagnosis, risk-stratification, and management. Am J Hematol 91: 151-165

4. Agar NS, Wedgeworth E, Crichton S et al (2010) Survival outcomes and prognostic factors in mycosis fungoides/Sezary syndrome: validation of the revised International Society for Cutaneous Lymphomas/European Organisation for Research and Treatment of Cancer staging proposal. J Clin Oncol 28:4730-4739

5. Scarisbrick JJ, Prince HM, Vermeer MH et al (2015) Cutaneous lymphoma international consortium study of outcome in advanced stages of mycosis fungoides and Sezary syndrome: effect of specific prognostic markers on survival and development of a prognostic model. J Clin Oncol 33:3766-3773

6. Diwan AH, Prieto VG, Herling M et al (2005) Primary Sezary syndrome commonly shows low-grade cytologic atypia and an absence of epidermotropism. Am J Clin Pathol 123:510-515

7. Ferenczi K, Fuhlbrigge RC, Pinkus J et al (2002) Increased CCR4 expression in cutaneous T cell lymphoma. J Invest Dermatol 119: $1405-1410$

8. Kallinich T, Muche JM, Qin S et al (2003) Chemokine receptor expression on neoplastic and reactive T cells in the skin at different stages of mycosis fungoides. J Invest Dermatol 121:1045-1052

9. Campbell JJ, Clark RA, Watanabe R et al (2010) Sezary syndrome and mycosis fungoides arise from distinct T-cell subsets: a biologic rationale for their distinct clinical behaviors. Blood 116:767-771

10. Sugaya M, Morimura S, Suga H et al (2015) CCR4 is expressed on infiltrating cells in lesional skin of early mycosis fungoides and atopic dermatitis. J Dermatol 42:613-615

11. Fujita Y, Abe R, Sasaki M et al (2006) Presence of circulating CCR10+ T cells and elevated serum CTACK/CCL27 in the early stage of mycosis fungoides. Clin Cancer Res 12:2670-2675

12. Lu D, Duvic M, Medeiros LJ et al (2001) The T-cell chemokine receptor CXCR3 is expressed highly in low-grade mycosis fungoides. Am J Clin Pathol 115:413-421

13. Tensen CP, Vermeer MH, van der Stoop PM et al (1998) Epidermal interferon-gamma inducible protein-10 (IP-10) and 
monokine induced by gamma-interferon (Mig) but not IL-8 mRNA expression is associated with epidermotropism in cutaneous T cell lymphomas. J Invest Dermatol 111:222-226

14. Miyagaki T, Sugaya M (2014) Immunological milieu in mycosis fungoides and Sezary syndrome. J Dermatol 41:11-18

15. Krejsgaard T, Odum N, Geisler C et al (2012) Regulatory T cells and immunodeficiency in mycosis fungoides and Sezary syndrome. Leukemia 26:424-432

16. Litvinov IV, Tetzlaff MT, Rahme E et al (2015) Demographic patterns of cutaneous T-cell lymphoma incidence in Texas based on two different cancer registries. Cancer Med 4:1440-1447

17. Litvinov IV, Tetzlaff MT, Rahme E et al (2015) Identification of geographic clustering and regions spared by cutaneous T-cell lymphoma in Texas using 2 distinct cancer registries. Cancer 121: 1993-2003

18. Willerslev-Olsen A, Krejsgaard T, Lindahl LM et al (2013) Bacterial toxins fuel disease progression in cutaneous T-cell lymphoma. Toxins (Basel) 5:1402-1421

19. Choi J, Goh G, Walradt $\mathrm{T}$ et al (2015) Genomic landscape of cutaneous T cell lymphoma. Nat Genet 47:1011-1019

20. Ungewickell A, Bhaduri A, Rios E et al (2015) Genomic analysis of mycosis fungoides and Sezary syndrome identifies recurrent alterations in TNFR2. Nat Genet 47:1056-1060

21. Kiel MJ, Sahasrabuddhe AA, Rolland DC et al (2015) Genomic analyses reveal recurrent mutations in epigenetic modifiers and the JAK-STAT pathway in Sezary syndrome. Nat Commun 6

22. Wang L, Ni X, Covington KR et al (2015) Genomic profiling of Sezary syndrome identifies alterations of key $\mathrm{T}$ cell signaling and differentiation genes. Nat Genet 47:1426-1434

23. da Silva Almeida AC, Abate F, Khiabanian H et al (2015) The mutational landscape of cutaneous T cell lymphoma and Sezary syndrome. Nat Genet 47:1465-1470

24. Woollard WJ, Pullabhatla V, Lorenc A et al (2016) Candidate driver genes in Sezary syndrome: frequent perturbations of genes involved in genome maintenance and DNA repair. Blood 127:3387-3397

25. McGirt LY, Jia P, Baerenwald DA et al (2015) Whole-genome sequencing reveals oncogenic mutations in mycosis fungoides. Blood 126:508-519

26. Belloni B, Johansen N, Glass LF et al (2012) Recent advances in the management of cutaneous lymphomas. Semin Oncol 39:150 162

27. Kim EJ, Hess S, Richardson SK et al (2005) Immunopathogenesis and therapy of cutaneous T cell lymphoma. J Clin Invest 115:798812

28. Wood GS, Edinger A, Hoppe RT et al (1994) Mycosis fungoides skin lesions contain CD8+ tumor-infiltrating lymphocytes expressing an activated, MHC-restricted cytotoxic T-lymphocyte phenotype. J Cutan Pathol 21:151-156

29. Asadullah K, Friedrich M, Docke WD et al (1997) Enhanced expression of T-cell activation and natural killer cell antigens indicates systemic anti-tumor response in early primary cutaneous T-cell lymphoma. J Invest Dermatol 108:743-747

30. Bagot M, Echchakir H, Mami-Chouaib F et al (1998) Isolation of tumor-specific cytotoxic CD4+ and CD4 + CD8dim + T-cell clones infiltrating a cutaneous T-cell lymphoma. Blood 91: 4331-4341

31. Echchakir H, Bagot M, Dorothee $\mathrm{G}$ et al (2000) Cutaneous $\mathrm{T}$ cell lymphoma reactive $\mathrm{CD} 4+$ cytotoxic $\mathrm{T}$ lymphocyte clones display a Th1 cytokine profile and use a fas-independent pathway for specific tumor cell lysis. J Invest Dermatol 115:74-80

32. Vermeer MH, van Doom R, Dukers D et al (2001) CD8+ T cells in cutaneous T-cell lymphoma: expression of cytotoxic proteins, Fas ligand, and killing inhibitory receptors and their relationship with clinical behavior. J Clin Oncol 19:4322-4329

33. Hsi AC, Lee SJ, Rosman IS et al (2015) Expression of helper T cell master regulators in inflammatory dermatoses and primary cutaneous T-cell lymphomas: diagnostic implications. J Am Acad Dermatol 72:159-167

34. Hoppe RT, Medeiros LJ, Warnke RA et al (1995) CD8positive tumor-infiltrating lymphocytes influence the longterm survival of patients with mycosis fungoides. J Am Acad Dermatol 32:448-453

35. Berger CL, Wang N, Christensen I et al (1996) The immune response to class I-associated tumor-specific cutaneous T-cell lymphoma antigens. J Invest Dermatol 107:392-397

36. Bouaziz JD, Ortonne N, Giustiniani J et al (2005) Circulating natural killer lymphocytes are potential cytotoxic effectors against autologous malignant cells in Sezary syndrome patients. J Invest Dermatol 125:1273-1278

37. Abeni D, Frontani M, Sampogna F et al (2005) Circulating CD8+ lymphocytes, white blood cells, and survival in patients with mycosis fungoides. Br J Dermatol 153:324-330

38. Vowels BR, Lessin SR, Cassin M et al (1994) Th2 cytokine mRNA expression in skin in cutaneous T-cell lymphoma. J Invest Dermatol 103:669-673

39. Papadavid E, Economidou J, Psarra A et al (2003) The relevance of peripheral blood T-helper 1 and 2 cytokine pattern in the evaluation of patients with mycosis fungoides and Sezary syndrome. Br J Dermatol 148:709-718

40. Hahtola S, Tuomela S, Elo L et al (2006) Th1 response and cytotoxicity genes are down-regulated in cutaneous T-cell lymphoma. Clin Cancer Res 12:4812-4821

41. Geskin LJ, Viragova S, Stolz DB et al (2015) Interleukin-13 is overexpressed in cutaneous T-cell lymphoma cells and regulates their proliferation. Blood 125:2798-2805

42. Johnson VE, Vonderheid EC, Hess AD et al (2014) Genetic markers associated with progression in early mycosis fungoides. J Eur Acad Dermatol Venereol 28:1431-1435

43. Netchiporouk E, Litvinov IV, Moreau L et al (2014) Deregulation in STAT signaling is important for cutaneous T-cell lymphoma (CTCL) pathogenesis and cancer progression. Cell Cycle 13: 3331-3335

44. Axelrod PI, Lorber B, Vonderheid EC (1992) Infections complicating mycosis fungoides and Sezary syndrome. JAMA 267: 1354-1358

45. Miyagaki T, Sugaya M, Suga $\mathrm{H}$ et al (2012) Low herpesvirus entry mediator (HVEM) expression on dermal fibroblasts contributes to a Th2-dominant microenvironment in advanced cutaneous T-cell lymphoma. J Invest Dermatol 132:1280-1289

46. Bromley SK, Mempel TR, Luster AD (2008) Orchestrating the orchestrators: chemokines in control of T cell traffic. Nat Immunol 9:970-980

47. Kakinuma T, Sugaya M, Nakamura K et al (2003) Thymus and activation-regulated chemokine (TARC/CCL17) in mycosis fungoides: serum TARC levels reflect the disease activity of mycosis fungoides. J Am Acad Dermatol 48:23-30

48. Miyagaki T, Sugaya M, Suga H et al (2013) Increased CCL18 expression in patients with cutaneous T-cell lymphoma: association with disease severity and prognosis. J Eur Acad Dermatol Venereol 27:e60-e67

49. Tuzova M, Richmond J, Wolpowitz D et al (2015) CCR4+ T cell recruitment to the skin in mycosis fungoides: potential contributions by thymic stromal lymphopoietin and interleukin-16. Leuk Lymphoma 56:440-449

50. Miyagaki T, Sugaya M, Fujita $\mathrm{H}$ et al (2010) Eotaxins and CCR3 interaction regulates the Th2 environment of cutaneous T-cell lymphoma. J Invest Dermatol 130:2304-2311

51. Gunther C, Zimmermann N, Berndt N et al (2011) Up-regulation of the chemokine CCL18 by macrophages is a potential immunomodulatory pathway in cutaneous T-cell lymphoma. Am J Pathol 179:1434-1442 
52. Sallusto F, Mackay CR, Lanzavecchia A (1997) Selective expression of the eotaxin receptor CCR3 by human T helper 2 cells. Science 277:2005-2007

53. Islam SA, Ling MF, Leung J et al (2013) Identification of human CCR8 as a CCL18 receptor. J Exp Med 210:1889-1898

54. Duvic M, Pinter-Brown LC, Foss FM et al (2015) Phase 1/2 study of mogamulizumab, a defucosylated anti-CCR4 antibody, in previously treated patients with cutaneous T-cell lymphoma. Blood 125:1883-1889

55. Miyagaki T, Sugaya M, Suga H et al (2011) IL-22, but not IL-17, dominant environment in cutaneous T-cell lymphoma. Clin Cancer Res 17:7529-7538

56. Ito M, Teshima K, Ikeda S et al (2014) Micro RNA-150 inhibits tumor invasion and metastasis by targeting the chemokine receptor CCR6, in advanced cutaneous T-cell lymphoma. Blood 123: 1499-1511

57. Ikeda S, Kitadate A, Ito M et al (2016) Disruption of CCL20CCR6 interaction inhibits metastasis of advanced cutaneous Tcell lymphoma. Oncotarget 7:13563-13574

58. Asadullah K, Docke WD, Haeussler A et al (1996) Progression of mycosis fungoides is associated with increasing cutaneous expression of interleukin-10 mRNA. J Invest Dermatol 107:833-837

59. Asadullah K, Haeussler-Quade A, Gellrich S et al (2000) IL-15 and IL-16 overexpression in cutaneous T-cell lymphomas: stagedependent increase in mycosis fungoides progression. Exp Dermatol 9:248-251

60. Mishra A, La PK, Kwiatkowski S et al (2016) Mechanism, consequences and therapeutic targeting of abnormal IL-15 signaling in cutaneous T-cell lymphoma. Cancer Discov 6:986-1005

61. Blaschke V, Reich K, Middel P et al (1999) Expression of the CD4+ cell-specific chemoattractant interleukin-16 in mycosis fungoides. J Invest Dermatol 113:658-663

62. Krejsgaard T, Litvinov IV, Wang Y et al (2013) Elucidating the role of interleukin- $17 \mathrm{~F}$ in cutaneous T-cell lymphoma. Blood 122: 943-950

63. van Kester MS, Borg MK, Zoutman WH et al (2012) A metaanalysis of gene expression data identifies a molecular signature characteristic for tumor-stage mycosis fungoides. J Invest Dermatol 132:2050-2059

64. Ohmatsu H, Humme D, Gulati N et al (2014) IL32 is progressively expressed in mycosis fungoides independent of helper T-cell 2 and helper T-cell 9 polarization. Cancer Immunol Res 2:890-900

65. Suga H, Sugaya M, Miyagaki T et al (2014) The role of IL-32 in cutaneous T-cell lymphoma. J Invest Dermatol 134:1428-1435

66. Rook AH, Kubin M, Cassin M et al (1995) IL-12 reverses cytokine and immune abnormalities in Sezary syndrome. J Immunol 154:1491-1498

67. Wilcox RA, Wada DA, Ziesmer SC et al (2009) Monocytes promote tumor cell survival in T-cell lymphoproliferative disorders and are impaired in their ability to differentiate into mature dendritic cells. Blood 114:2936-2944

68. Krejsgaard T, Gjerdrum LM, Ralfkiaer E et al (2008) Malignant Tregs express low molecular splice forms of FOXP3 in Sezary syndrome. Leukemia 22:2230-2239

69. Richmond J, Tuzova M, Parks A et al (2011) Interleukin-16 as a marker of Sezary syndrome onset and stage. J Clin Immunol 31: $39-50$

70. Ciree A, Michel L, Camilleri-Broet S et al (2004) Expression and activity of IL-17 in cutaneous T-cell lymphomas (mycosis fungoides and Sezary syndrome. Int J Cancer 112:113-120

71. Krejsgaard T, Ralfkiaer U, Clasen-Linde E et al (2011) Malignant cutaneous T-cell lymphoma cells express IL-17 utilizing the Jak3/Stat 3 signaling pathway. J Invest Dermatol 131:1331-1338

72. Fontao L, Brembilla NC, Masouye I et al (2012) Interleukin-17 expression in neutrophils and Th17 cells in cutaneous T-cell lymphoma associated with neutrophilic infiltrate of the skin. Br J Dermatol 166:687-689

73. Wolk K, Mitsui H, Witte K et al (2014) Deficient cutaneous antibacterial competence in cutaneous T-cell lymphomas: role of Th2mediated biased Th17 function. Clin Cancer Res 20:5507-5516

74. Franck N, Carlotti A, Gorin I et al (2005) Mycosis fungoides-type cutaneous T-cell lymphoma and neutrophilic dermatosis. Arch Dermatol 141:353-356

75. Nielsen M, Nissen MH, Gerwien J et al (2002) Spontaneous interleukin-5 production in cutaneous T-cell lymphoma lines is mediated by constitutively activated stat 3. Blood 99:973-977

76. Guenova E, Watanabe R, Teague JE et al (2013) TH2 cytokines from malignant cells suppress TH1 responses and enforce a global TH2 bias in leukemic cutaneous T-cell lymphoma. Clin Cancer Res 19:3755-3763

77. Zhang Q, Nowak I, Vonderheid EC et al (1996) Activation of Jak/ STAT proteins involved in signal transduction pathway mediated by receptor for interleukin 2 in malignant $\mathrm{T}$ lymphocytes derived from cutaneous anaplastic large T-cell lymphoma and Sezary syndrome. Proc Natl Acad Sci USA 93:9148-9153

78. Zhang Q, Raghunath PN, Vonderheid E et al (2000) Lack of phosphotyrosine phosphatase SHP-1 expression in malignant Tcell lymphoma cells results from methylation of the SHP-1 promoter. Am J Pathol 157:1137-1146

79. Qin JZ, Kamarashev J, Zhang CL et al (2001) Constitutive and interleukin-7- and interleukin-15-stimulated DNA binding of STAT and novel factors in cutaneous T cell lymphoma cells. $\mathrm{J}$ Invest Dermatol 117:583-589

80. Sommer VH, Clemmensen OJ, Nielsen O et al (2004) In vivo activation of STAT3 in cutaneous T-cell lymphoma. Evidence for an antiapoptotic function of STAT3. Leukemia 18:1288-1295

81. Krejsgaard T, Vetter-Kauczok CS, Woetmann A et al (2006) Jak3and JNK-dependent vascular endothelial growth factor expression in cutaneous T-cell lymphoma. Leukemia 20:1759-1766

82. Krejsgaard T, Willerslev-Olsen A, Lindahl LM et al (2014) Staphylococcal enterotoxins stimulate lymphoma-associated immune dysregulation. Blood 124:761-770

83. Willerslev-Olsen A, Krejsgaard T, Lindahl LM et al (2016) Staphylococcal enterotoxin a (SEA) stimulates STAT3 activation and IL-17 expression in cutaneous T-cell lymphoma. Blood 127: $1287-1296$

84. Litvinov IV, Cordeiro B, Fredholm S et al (2014) Analysis of STAT4 expression in cutaneous T-cell lymphoma (CTCL) patients and patient-derived cell lines. Cell Cycle 13:2975-2982

85. Nebozhyn M, Loboda A, Kari L et al (2006) Quantitative PCR on 5 genes reliably identifies CTCL patients with $5 \%$ to $99 \%$ circulating tumor cells with $90 \%$ accuracy. Blood 107:3189-3196

86. van Doom R, Dijkman R, MH V et al (2004) Aberrant expression of the tyrosine kinase receptor EphA4 and the transcription factor twist in Sezary syndrome identified by gene expression analysis. Cancer Res 64:5578-5586

87. Kopp KL, Ralfkiaer U, Gjerdrum LM et al (2013) STAT5mediated expression of oncogenic miR-155 in cutaneous T-cell lymphoma. Cell Cycle 12:1939-1947

88. Litvinov IV, Pehr K, Sasseville D (2013) Connecting the dots in cutaneous T cell lymphoma (CTCL): STAT5 regulates malignant T cell proliferation via miR-155. Cell Cycle 12:2172-2173

89. Furudate S, Fujimura T, Kakizaki A et al (2016) Tumor-associated M2 macrophages in mycosis fungoides acquire immunomodulatory function by interferon alpha and interferon gamma. J Dermatol Sci 83:182-189

90. Bao L, Shi VY, Chan LS (2012) IL-4 regulates chemokine CCL26 in keratinocytes through the Jak1, 2/stat 6 signal transduction pathway: implication for atopic dermatitis. Mol Immunol 50:9197 
91. Fujita H, Asahina A, Sugaya M et al (2005) Differential production of Th1- and Th2-type chemokines by mouse Langerhans cells and splenic dendritic cells. J Invest Dermatol 124:343-350

92. Ohta K, Shigeishi H, Taki M et al (2008) Regulation of CXCL9/ 10/11 in oral keratinocytes and fibroblasts. J Dent Res 87:1160 1165

93. Kodelja V, Muller C, Politz O et al (1998) Alternative macrophage activation-associated CC-chemokine-1, a novel structural homologue of macrophage inflammatory protein-1 alpha with a Th2associated expression pattern. J Immunol 160:1411-1418

94. Antonelli A, Ferrari SM, Giuggioli D et al (2014) Chemokine (C$\mathrm{X}-\mathrm{C}$ motif) ligand (CXCL)10 in autoimmune diseases. Autoimmun Rev 13:272-280

95. Zhang Q, Wang HY, Wei F et al (2014) Cutaneous T cell lymphoma expresses immunosuppressive CD80 (B7-1) cell surface protein in a STAT5-dependent manner. J Immunol 192:2913-2919

96. Chen L, Flies DB (2013) Molecular mechanisms of T cell costimulation and co-inhibition. Nat Rev Immunol 13:227-242

97. Samimi S, Benoit B, Evans K et al (2010) Increased programmed death-1 expression on CD4+ T cells in cutaneous T-cell lymphoma: implications for immune suppression. Arch Dermatol 146: $1382-1388$

98. Abraham RM, Zhang Q, Odum $\mathrm{N}$ et al (2011) The role of cytokine signaling in the pathogenesis of cutaneous T-cell lymphoma. Cancer Biol Ther 12:1019-1022

99. Wilcox RA, Feldman AL, Wada DA et al (2009) B7-H1 (PD-L1, CD274) suppresses host immunity in T-cell lymphoproliferative disorders. Blood 114:2149-2158

100. Kantekure K, Yang Y, Raghunath P et al (2012) Expression patterns of the immunosuppressive proteins PD-1/CD279 and PDL1/CD274 at different stages of cutaneous T-cell lymphoma/ mycosis fungoides. Am J Dermatopathol 34:126-128

101. Munir S, Andersen GH, Woetmann A et al (2013) Cutaneous T cell lymphoma cells are targets for immune checkpoint ligand PDL1-specific, cytotoxic T cells. Leukemia 27:2251-2253

102. Ni X, Hazarika P, Zhang C et al (2001) Fas ligand expression by neoplastic $\mathrm{T}$ lymphocytes mediates elimination of CD8+ cytotoxic $\mathrm{T}$ lymphocytes in mycosis fungoides: a potential mechanism of tumor immune escape? Clin Cancer Res 7:2682-2692

103. Ni X, Zhang C, Talpur R et al (2005) Resistance to activationinduced cell death and bystander cytotoxicity via the fas/fas ligand pathway are implicated in the pathogenesis of cutaneous $\mathrm{T}$ cell lymphomas. J Invest Dermatol 124:741-750

104. Zoi-Toli O, Vermeer MH, De VE et al (2000) Expression of Fas and Fas-ligand in primary cutaneous T-cell lymphoma (CTCL): association between lack of Fas expression and aggressive types of CTCL. Br J Dermatol 143:313-319

105. Nagasawa T, Takakuwa T, Takayama $\mathrm{H}$ et al (2004) Fas gene mutations in mycosis fungoides: analysis of laser capturemicrodissected specimens from cutaneous lesions. Oncology 67: 130-134

106. Contassot E, Kerl K, Roques S et al (2008) Resistance to FasL and tumor necrosis factor-related apoptosis-inducing ligand-mediated apoptosis in Sezary syndrome T-cells associated with impaired death receptor and FLICE-inhibitory protein expression. Blood 111:4780-4787

107. Esmailzadeh S, Huang Y, MW S et al (2015) BIN1 tumor suppressor regulates Fas/Fas ligand-mediated apoptosis through cFLIP in cutaneous T-cell lymphoma. Leukemia 29:1402-1413

108. Kasprzycka M, Zhang Q, Witkiewicz A et al (2008) Gamma csignaling cytokines induce a regulatory $\mathrm{T}$ cell phenotype in malignant CD4+ T lymphocytes. J Immunol 181:2506-2512

109. Chung JS, Shiue LH, Duvic M et al (2011) Sezary syndrome cells overexpress syndecan-4 bearing distinct heparan sulfate moieties that suppress T-cell activation by binding DC-HIL and trapping TGF-beta on the cell surface. Blood 117:3382-3390
110. Kadin ME, Cavaille-Coll MW, Gertz R et al (1994) Loss of receptors for transforming growth factor beta in human T-cell malignancies. Proc Natl Acad Sci USA 91:6002-6006

111. Dulmage BO, Geskin LJ (2013) Lessons learned from gene expression profiling of cutaneous T-cell lymphoma. Br J Dermatol 169:1188-1197

112. Nakahata S, Yamazaki S, Nakauchi H et al (2010) Downregulation of ZEB1 and overexpression of Smad 7 contribute to resistance to TGF-beta 1-mediated growth suppression in adult T-cell leukemia/ lymphoma. Oncogene 29:4157-4169

113. Brender C, Lovato P, Sommer VH et al (2005) Constitutive SOCS-3 expression protects T-cell lymphoma against growth inhibition by IFNalpha. Leukemia 19:209-213

114. Dobbeling U, Dummer R, Laine E et al (1998) Interleukin-15 is an autocrine/paracrine viability factor for cutaneous T-cell lymphoma cells. Blood 92:252-258

115. Marzec M, Halasa K, Kasprzycka M et al (2008) Differential effects of interleukin-2 and interleukin-15 versus interleukin-21 on CD4+ cutaneous T-cell lymphoma cells. Cancer Res 68: 1083-1091

116. Thode C, Woetmann A, Wandall HH et al (2015) Malignant T cells secrete galectins and induce epidermal hyperproliferation and disorganized stratification in a skin model of cutaneous Tcell lymphoma. J Invest Dermatol 135:238-246

117. Izban KF, Ergin M, Qin JZ et al (2000) Constitutive expression of NF-kappa B is a characteristic feature of mycosis fungoides: implications for apoptosis resistance and pathogenesis. Hum Pathol 31:1482-1490

118. Sors A, Jean-Louis F, Pellet C et al (2006) Down-regulating constitutive activation of the NF-kappa B canonical pathway overcomes the resistance of cutaneous T-cell lymphoma to apoptosis. Blood 107:2354-2363

119. Kopp KL, Kauczok CS, Lauenborg B et al (2010) COX-2dependent PGE(2) acts as a growth factor in mycosis fungoides (MF). Leukemia 24:1179-1185

120. Kopp KL, Dabelsteen S, Krejsgaard T et al (2010) COX-2 is a novel target in therapy of mycosis fungoides. Leukemia 24:21272129

121. Kalinski P (2012) Regulation of immune responses by prostaglandin E2. J Immunol 188:21-28

122. Rabenhorst A, Schlaak M, Heukamp LC et al (2012) Mast cells play a protumorigenic role in primary cutaneous lymphoma. Blood 120:2042-2054

123. Ionescu MA, Rivet J, Daneshpouy M et al (2005) In situ eosinophil activation in 26 primary cutaneous T-cell lymphomas with blood eosinophilia. J Am Acad Dermatol 52:32-39

124. Kural YB, Su O, Onsun N et al (2010) Atopy, IgE and eosinophilic cationic protein concentration, specific IgE positivity, eosinophil count in cutaneous T cell lymphoma. Int J Dermatol 49:390-395

125. Fredholm S, Gjerdrum LM, Willerslev-Olsen A et al (2014) STAT3 activation and infiltration of eosinophil granulocytes in mycosis fungoides. Anticancer Res 34:5277-5286

126. Wu X, Schulte BC, Zhou Y et al (2014) Depletion of M2-like tumor-associated macrophages delays cutaneous T-cell lymphoma development in vivo. J Invest Dermatol 134:2814-2822

127. Sugaya M, Miyagaki T, Ohmatsu $\mathrm{H}$ et al (2012) Association of the numbers of CD163(+) cells in lesional skin and serum levels of soluble CD163 with disease progression of cutaneous T cell lymphoma. J Dermatol Sci 68:45-51

128. Davoine F, Lacy P (2014) Eosinophil cytokines, chemokines, and growth factors: emerging roles in immunity. Front Immunol 5

129. Ehrentraut S, Schneider B, Nagel S et al (2016) Th17 cytokine differentiation and loss of plasticity after SOCS1 inactivation in a cutaneous T-cell lymphoma. Oncotarget. doi:10.18632 /oncotarget. 9077 
130. Berger CL, Hanlon D, Kanada D et al (2002) The growth of cutaneous T-cell lymphoma is stimulated by immature dendritic cells. Blood 99:2929-2939

131. Komohara Y, Jinushi M, Takeya M (2014) Clinical significance of macrophage heterogeneity in human malignant tumors. Cancer Sci 105:1-8

132. Vacca A, Moretti S, Ribatti D et al (1997) Progression of mycosis fungoides is associated with changes in angiogenesis and expression of the matrix metalloproteinases 2 and 9. Eur J Cancer 33: $1685-1692$

133. Lauenborg B, Christensen L, Ralfkiaer U et al (2015) Malignant T cells express lymphotoxin alpha and drive endothelial activation in cutaneous T cell lymphoma. Oncotarget 6:15235-15249

134. Pileri A, Agostinelli C, Righi S et al (2015) Vascular endothelial growth factor a (VEGFA) expression in mycosis fungoides. Histopathology 66:173-181

135. Pedersen IH, Willerslev-Olsen A, Vetter-Kauczok C et al (2013) Vascular endothelial growth factor receptor-3 expression in mycosis fungoides. Leuk Lymphoma 54:819-826

136. Rook AH, Wood GS, Yoo EK et al (1999) Interleukin-12 therapy of cutaneous T-cell lymphoma induces lesion regression and cytotoxic T-cell responses. Blood 94:902-908

137. Suchin KR, Junkins-Hopkins JM, Rook AH (2002) Treatment of stage IA cutaneous T-cell lymphoma with topical application of the immune response modifier imiquimod. Arch Dermatol 138: 1137-1139

138. Dummer R, Hassel JC, Fellenberg F et al (2004) Adenovirusmediated intralesional interferon-gamma gene transfer induces tumor regressions in cutaneous lymphomas. Blood 104:1631-1638

139. Wysocka M, Benoit BM, Newton S et al (2004) Enhancement of the host immune responses in cutaneous T-cell lymphoma by $\mathrm{CpG}$ oligodeoxynucleotides and IL-15. Blood 104:4142-4149

140. Duvic M, Sherman ML, Wood GS et al (2006) A phase II openlabel study of recombinant human interleukin-12 in patients with stage IA, IB, or IIA mycosis fungoides. J Am Acad Dermatol 55: 807-813

141. Wysocka M, Newton S, Benoit BM et al (2007) Synthetic imidazoquinolines potently and broadly activate the cellular immune response of patients with cutaneous T-cell lymphoma: synergy with interferon-gamma enhances production of interleukin12. Clin Lymphoma Myeloma 7:524-534

142. Kim YH, Girardi M, Duvic M et al (2010) Phase I trial of a Tolllike receptor 9 agonist, PF-3512676 (CPG 7909), in patients with treatment-refractory, cutaneous T-cell lymphoma. J Am Acad Dermatol 63:975-983

143. Accart N, Urosevic-Maiwald M, Dummer R et al (2013) Lymphocytic infiltration in the cutaneous lymphoma microenvironment after injection of TG 1042. J Transl Med 11:226

144. Rook AH, Gelfand JM, Wysocka M et al (2015) Topical resiquimod can induce disease regression and enhance T-cell effector functions in cutaneous T-cell lymphoma. Blood 126:14521461

145. Jackow CM, Cather JC, Hearne V et al (1997) Association of erythrodermic cutaneous T-cell lymphoma, superantigen-positive Staphylococcus aureus, and oligoclonal T-cell receptor V beta gene expansion. Blood 89:32-40

146. Talpur R, Bassett R, Duvic M (2008) Prevalence and treatment of Staphylococcus aureus colonization in patients with mycosis fungoides and Sezary syndrome. Br J Dermatol 159:105-112

147. Nguyen V, Huggins RH, Lertsburapa T et al (2008) Cutaneous Tcell lymphoma and Staphylococcus aureus colonization. J Am Acad Dermatol 59:949-952

148. Woetmann A, Lovato P, Eriksen KW et al (2007) Nonmalignant T cells stimulate growth of T-cell lymphoma cells in the presence of bacterial toxins. Blood 109:3325-3332
149. Tokura Y, Yagi H, Ohshima A et al (1995) Cutaneous colonization with staphylococci influences the disease activity of Sezary syndrome: a potential role for bacterial superantigens. Br J Dermatol 133:6-12

150. Duvic M, Hester JP, Lemak NA (1996) Photopheresis therapy for cutaneous T-cell lymphoma. J Am Acad Dermatol 35:573-579

151. van Doom R, Slieker RC, Boonk SE et al (2016) Epigenomic analysis of Sezary syndrome defines patterns of aberrant DNA methylation and identifies diagnostic markers. J Invest Dermatol 136:1876-1884

152. van Doom R, Zoutman WH, Dijkman R et al (2005) Epigenetic profiling of cutaneous T-cell lymphoma: promoter hypermethylation of multiple tumor suppressor genes including BCL7a, PTPRG, and p 73. J Clin Oncol 23:3886-3896

153. Yu H, Pardoll D, Jove R (2009) STATs in cancer inflammation and immunity: a leading role for STAT3. Nat Rev Cancer 9:798-809

154. Cheah MT, Chen JY, Sahoo D et al (2015) CD14-expressing cancer cells establish the inflammatory and proliferative tumor microenvironment in bladder cancer. Proc Natl Acad Sci USA 112: 4725-4730

155. Ma X, Aoki T, Tsuruyama T et al (2015) Definition of prostaglandin E2-EP2 signals in the colon tumor microenvironment that amplify inflammation and tumor growth. Cancer Res 75:28222832

156. Lou Y, Diao L, Cuentas ER et al (2016) Epithelial-mesenchymal transition is associated with a distinct tumor microenvironment including elevation of inflammatory signals and multiple immune checkpoints in lung adenocarcinoma. Clin Cancer Res 22:3630 3642

157. Bais AG, Beckmann I, Lindemans $\mathrm{J}$ et al (2005) A shift to a peripheral Th2-type cytokine pattern during the carcinogenesis of cervical cancer becomes manifest in CIN III lesions. J Clin Pathol 58:1096-1100

158. Tosolini M, Kirilovsky A, Mlecnik B et al (2011) Clinical impact of different classes of infiltrating T cytotoxic and helper cells (Th1, th2, treg, th17) in patients with colorectal cancer. Cancer Res 71: $1263-1271$

159. Kristensen VN, Vaske CJ, Ursini-Siegel J et al (2012) Integrated molecular profiles of invasive breast tumors and ductal carcinoma in situ (DCIS) reveal differential vascular and interleukin signaling. Proc Natl Acad Sci USA 109:2802-2807

160. Gaur P, Singh AK, Shukla NK et al (2014) Inter-relation of Th1, Th2, Th17 and Treg cytokines in oral cancer patients and their clinical significance. Hum Immunol 75:330-337

161. Datta J, Berk E, Xu S et al (2015) Anti-HER2 CD4(+) T-helper type 1 response is a novel immune correlate to pathologic response following neoadjuvant therapy in HER2-positive breast cancer. Breast Cancer Res 17

162. Peng D, Kryczek I, Nagarsheth N et al (2015) Epigenetic silencing of TH1-type chemokines shapes tumour immunity and immunotherapy. Nature 527:249-253

163. Si W, Huang W, Zheng Y et al (2015) Dysfunction of the reciprocal feedback loop between GATA3- and ZEB2-nucleated repression programs contributes to breast cancer metastasis. Cancer Cell $27: 822-836$

164. De ML, Wormann S, Brunetto E et al (2016) Basophil recruitment into tumor-draining lymph nodes correlates with Th2 inflammation and reduced survival in pancreatic cancer patients. Cancer Res 76:1792-1803

165. Nagarsheth N, Peng D, Kryczek I et al (2016) PRC2 epigenetically silences Th1-type chemokines to suppress effector T-cell trafficking in colon cancer. Cancer Res 76:275-282

166. Subbaramaiah K, Morris PG, Zhou XK et al (2012) Increased levels of COX-2 and prostaglandin E2 contribute to elevated aromatase expression in inflamed breast tissue of obese women. Cancer Discov 2:356-365 